\title{
Ambient Intelligence for Rehabilitation: A Survey
}

\author{
Asmita Gorave \\ Assistant Professor \\ MIT College of Engineering \\ Kothrud, Pune, Maharashtra
}

\begin{abstract}
Rehabilitation is defined as a set of measures that assist individuals who experience, or are likely to experience, disability to achieve and maintain optimal functioning in interaction with their environments. Ambient Intelligence (AmI) refers to a digital environment that proactively, but sensibly, supports people in their daily lives. AmI is useful in order to rehabilitate patients. In this paper, a survey of AmI for rehabilitation is presented.
\end{abstract}

\section{General Terms}

Ambient Intelligence

\section{Keywords}

Ambient Intelligence, Rehabilitation, Health care, Therapy

\section{INTRODUCTION}

\subsection{What is rehabilitation?}

Rehabilitation is an important aspect in order to cure any disease. Disease cannot be cured merely by medication. Patient's mental health is equally important as her/his physical health in order to cure a disease. Rehabilitation is defined as a set of measures that assist individuals who experience, or are likely to experience, disability to achieve and maintain optimal functioning in interaction with their environments [1]. In today's world people face various chronic diseases such as cancer. Rehabilitation plays a crucial role in the treatment of such chronic diseases. E.g. Rehabilitation can help a cancer patient to improve physical strength, reduce anxiety and depression, reduce hospital stays, manage symptoms of cancer, etc. [2].

\subsection{What is Ambient Intelligence?}

The European Commission's Information Society Technologies Advisory Group (ISTAG) introduced the concept of Ambient Intelligence (AmI). AmI refers to a digital environment that proactively, but sensibly, supports people in their daily lives. The concept of AmI provides a vision of the information society, where the emphasis is on greater user-friendliness, more efficient services support, user empowerment, and support for human interactions [3]. AmI means making the environment smart. Here the surrounding of the person helps her/him to live a better life. Ambience of the person supports her/him. Unobtrusive, interconnected, adaptable, dynamic, embedded and intelligent are the features of AmI. Processors and sensors is the integral part of AmI. E.g. sensors may be embedded in our clothes and clothes can communicate with us. The key features of AmI are intelligence and embedding [4]. AmI has various characteristics such as [5]:

Context Aware: It exploits the contextual and situational information.

Personalized: It is personalized and tailored to the needs of each individual
Anticipatory: It can anticipate the needs of an individual without the conscious mediation of the individual

Adaptive: It adapts to the changing needs of individuals.

Ubiquity: It is embedded and integrated into our everyday environments

Transparency: It recedes into the background of our daily life in an unobtrusive way.

\subsection{Applications of AmI:}

There are many application domains of AmI. One of the application domains is health care [6].

AmI can be useful in health care for the following purposes [5]:

Continuous Monitoring

Assisted Living

Therapy and Rehabilitation

Persuasive Well-being Applications

Emotional Well-being

Smart hospitals.

So as per paper [5], it is clear that AmI can be used for rehabilitation purpose.

In this paper the detailed survey of AmI for rehabilitation is presented.

The rest of the paper is organized as follows: Section 2 describes the rehabilitation challenges. Section 3 presents the detailed survey on rehabilitation using Ambient Intelligence. Section 4 is the Discussions section. Section 5 presents conclusion and future research directions.

\section{REHABILITATION CHALLENGES}

Rehabilitation Process steps are as mentioned below [1]:

1. Identify problems and needs

2. Relate problems to modifiable and limiting factors

3. Define target problems and target mediators, select appropriate measures

4. Plan, Implement and coordinate interventions

5. Assess effects

Rehabilitation measures are divided into three categories [1]

1. Rehabilitation medicine:

Rehabilitation doctors give medicines to patients for better functioning

2. Therapy:

Therapy measures include: 
Training, exercises and compensatory strategies

Education

Support and Counselling

3. Assistive technologies: Assistive technologies contain the devices which assist the disabled people.

Challenges in rehabilitation are as mentioned below:

1. The main challenge is the mind-set of the patient. As the patient is physically ill, she/he become mentally ill also. If the patient is mentally ill, no medicine can cure her/him.

2. The environment of the patient should support her/him. If the environment surrounding the patient has negative thoughts, the patient will take more time to recover

3. Availability of rehabilitation center is another challenge. Patient should be allowed to take the therapy at home also.

4. The high cost of rehabilitation is a major issue.

As patient's surrounding and environment can affect the rehabilitation, AmI can become a useful domain. In the next section, we present a survey of AmI for rehabilitation considering rehabilitation measures and challenges.

\section{AmI FOR REHABILITATION}

As per [7], the concept of AmI provides a vision of the information society where the emphasis is on greater userfriendliness, more efficient service support, user empowerment, and support for human interactions. People are surrounded by intelligent intuitive interfaces that are embedded in all kinds of objects and an environment that is capable of recognizing and responding to the presence of different individuals in a seamless, unobtrusive and often invisible way. In this paper different scenarios of AmI are presented. [5] presents the use of AmI in health care. Most useful feature of AmI is Intelligent Mixed Reality (IMR). IMR can be used to seamlessly integrate computer interfaces into real environment. [5] describes the application of AmI in managed care. [8] presents the use of AmI for assisting elderly people. The goal of ambient assisted living solutions is to apply ambient intelligence technology to enable people with specific demands, e.g. handicapped or elderly, to live in their preferred environment longer.

Table 1. AmI for Rehabilitation

\begin{tabular}{|c|c|c|}
\hline Measure & Challenge & Papers \\
\hline $\begin{array}{c}\text { Assistive } \\
\text { Technology }\end{array}$ & Environment & $\begin{array}{c}{[8],[9],[10],[18],[19],} \\
{[20],[21]}\end{array}$ \\
\hline $\begin{array}{c}\text { Therapy } \\
\text { (Training and } \\
\text { Exercise) }\end{array}$ & Mind-set & {$[11][14][17],[23]$} \\
\hline $\begin{array}{c}\text { Therapy } \\
\text { Support and } \\
\text { Counselling) }\end{array}$ & $\begin{array}{c}\text { Availability of } \\
\text { Rehabilitation } \\
\text { Center }\end{array}$ & {$[12],[13],[15],[22]$} \\
\hline $\begin{array}{c}\text { Rehabilitation } \\
\text { medicine }\end{array}$ & Mind-set & {$[16]$} \\
\hline
\end{tabular}

The survey of Rehabilitation using AmI with its challenges and measures is shown in Table 1. [9] presents the concept of universal access. Universal access means information technology can be used by anyone at any place and at any time. This is also known as ubiquitous computing. [10] presents an integrated system concept for the living assistance domain based on AmI technology. Sensor Networks can be useful for rehabilitation in Health Care domain [11]. [12] proposes the ubiquitous rehabilitation center. [13] describes requirements of a system for cardiac telerehabilitation at home. [6] presents a survey of rehabilitation using AmI in health care domain. [14] presents a system which uses AmI for improving health of patient suffering from chronic obstructive pulmonary disease (COPD) by training and exercise. [15] presents different wearable sensors and a system for telerehabilitation. [16] deals with using sensor networks for telemedicine. [17] depicts a system to treat people with Acquired Brain Injury (ABI) using specific devices to control patient's movements during her/his rehabilitation process. [18] presents the Multi-Agent Architecture (MAS) of a healthcare AmI system to treat older people's motor impairment problems by using specific devices to control the patient's movement.

[19] illustrates the concept of "Living Labs" using ambient technologies. "Living Labs" show use of sensors to monitor human behaviour in real life environment. [20] shows some solution based on AmI using assistive technology to help elderly people. These techniques deal with physical and cognitive rehabilitation. [21] survey ambient assisted living. [22] present the design, development and evaluation of a haptic enhanced tele-rehabilitation system for massage therapy of the back using the Vybe haptic gaming pad. The Stroke Rehab Exerciser by Philips Research [23] guides the patient through a sequence of exercises for motor retraining, which are prescribed by the physiotherapist and uploaded to a patient unit The system lies on a wireless inertial sensor system aimed at recording the patient's movements, analyses the data for deviations from a personal movement target, and provides feedback to the patient and the therapist

\section{DICUSSIONS}

The survey of AmI for rehabilitation of patients is presented in section 3. It is clear that rehabilitation is very important aspect to cure a patient. There are various methods of rehabilitation. However, rehabilitation faces many challenges. In-order to get maximum effect of rehabilitation methods, the patient should follow the therapy without disturbance. We can make the environment of the patient smart, so that patient can get maximum benefit to the rehabilitation treatment.

In order to make the environment smart, we can use different sensors, different small devices. These sensors and devices are useful to interact with each other and make the ambience/environment intelligent. There are various areas of rehabilitation where we can use AmI technology. AmI is most useful for assisted living of elderly people. AmI will no doubt will create positive environment for people. It will help people to live a better life.

\section{CONCLUSION AND FUTURE RESEARCH DIRECTIONS}

It can be concluded from the above discussion that, AmI becomes a very useful area in case of rehabilitation of patients. This paper gives overview of various challenges faced by rehabilitation of patients. This paper also presents the various measures of rehabilitation. The main contribution of this paper is the survey of rehabilitation using AmI. This 
paper classifies the previous research in terms of rehabilitation measures and challenges. There is still a scope of research in in this field.

\section{REFERENCES}

[1] World Health Organization, Chapter 4- Rehabilitation, https://www.who.int/disabilities/world_report/2011/chapt er4.pdf?ua $=1$.

[2] Cancer.Net, https://www.cancer.net/survivorship/followcare-after-cancer-treatment/rehabilitation.

[3] Fariba Sadri, "Ambient Intelligence: A Survey", ACM Computing Surveys (CSUR), 2011.

[4] A Gaggioli, "Optimal Experince in Ambient Intelligence", Ambient Intelligence 35 G. Riva, F. Vatalaro, F. Davide, M. Alcañiz (Eds.), pp. 35-43, 2005.

[5] G. Acampora, D.J. Cook, P.Rashidi, A.V. Vasilakos, "A Survey on Ambient Intelligence in Health Care", Proc. IEEE Inst Electr Electron Eng, Vol. 101, No.12, pp. 2470-2494, 2013

[6] G. Riva, "Ambient Intelligence in Health Care", CyberPsychology and Behavior, Vol.6, No.3, pp. 295300, 2003.

[7] Ducatel, K., Bogdanowicz, M., Scapolo, F., et al. "Scenarios for ambient intelligence in 2010" (ISTAG).

[8] T. Kleinberger, M. Becker, E. Ras, A. Holzinger, P. Müller, "Ambient Intelligence in Assisted Living: Enable Elderly People to Handle Future Interfaces”, Springer-Verlag Berlin Heidelberg , pp. 103-112, 2007.

[9] P. L. Emiliani, C. Stephanidis, "Universal access to ambient intelligence environments: Opportunities and challenges for people with disabilities", IBM Systems Journals, Vol.44, No.3, pp. 605-619, 2005

[10] J.Nehmer, A. Karshmer, M. Becker, R. Lamm, "Living Assistance Systems - An Ambient Intelligence Approach -“, ICSE, Shanghai, May 24-26, 2006.

[11] S. Patel, H. Park, P. Bonato, L. Chan, and M. Rodgers, "A review of wearable sensors and systems with application in rehabilitation," J. NeuroEng. Rehabil., vol. 9, no. 1, 2012.

[12] B. P. Jarochowski, S. Shin, D. Ryu, and H. Kim, "Ubiquitous rehabilitation center: An implementation of a wireless sensor network based rehabilitation management system," in Proc. Int. Conf. Technol., Washington, DC, USA, 2007, Conv. Inf. pp. 2349-2358.

[13] E. Piotrowicz, A. Jasionowska, M. BanaszakBednarczyk, J. Gwilkowska and R. Piotrowicz, "ECG telemonitoring during home-based cardiac rehabilitation in heart failure patients,' J. Telemed. Telecare, vol. 18, no. 4, pp. 193-197, 2012.

[14] A. Helmer, B. Song, W. Ludwig, M. Schulze, M.
The following are the major research areas: Using AmI for rehabilitation of chronic diseases such as cancer, Using AmI for different therapy to improve mental state of the patient.

Eichelberg, A. Hein, U. Tegtbur, R. Kayser, R. Haux, and M. Marschollek, "A sensor-enhanced health information system to support automatically controlled exercise training of COPD patients," in Proc. 4th Int. Conf. Perv. Comput. Technol. Healthcare, Mar. 2010.

[15] J. Winters and Y. Wang, "Wearable sensors and telerehabilitation," IEEE Eng. Med. Biol. Mag., vol. 22, no. 3, pp. 56-65, May-Jun. 2003.

[16] C. Poon, Y.-T. Zhang, and S.-D. Bao, "A novel biometrics method to secure wireless body area sensor networks for telemedicine and m-health," IEEE ommun. Mag., vol. 44, no. 4, pp. 73-81, Apr. 2006.

[17] C.Roda, A. Rodriguez, V. Lopez-Jaquero, E. Navarro, P.Gonzalez, "A Multi-agent System for Acquired Brain Injuri rehabilitation in Ambient Intelligence Environment", Nurocomputing, Vol. 231, pp.11-18, 2017.

[18] C.Roda, A. Rodriguez, V. Lopez-Jaquero, E. Navarro, P.Gonzalez, "A Multi-agent System in Ambient intelligence for the Physical Rehabilitation of Older People", Trends in Practical Applications of Agents, Multi-Agent Systems and Sustainability. Advances in Intelligent Systems and Computing, vol 372. Springer, pp. 113-123, 2015.

[19] M. Korman, P. L. Weiss \& R. Kizony (2016) Living Labs: overview of ecological approaches for health promotion and rehabilitation, Disability and Rehabilitation, Vol. 38 No.7, pp. 613-619, 2016

[20] M. Oliver, P. González, F. Montero , J.P. Molina, A Fernández-Caballero, "Smart Computer-Assisted Cognitive Rehabilitation for the Ageing Population.", In: Lindgren H. et al. (eds) Ambient Intelligence- Software and Applications - 7th International Symposium on Ambient Intelligence (ISAmI 2016). ISAmI 2016. Advances in Intelligent Systems and Computing, vol 476. Springer, pp. 197-205, 2016

[21] D. Monekosso, F. Florez-Revuelta and P. Remagnino, “Ambient Assisted Living”, IEEE, pp.1541-1672, 2015

[22] C. Ramírez-Fernández et al., "GoodVybesConnect: A Real-Time Haptic Enhanced Tele-Rehabilitation System for Massage Therapy”. In: García C., Caballero-Gil P., Burmester M., Quesada-Arencibia A. (eds) Ubiquitous Computing and Ambient Intelligence. UCAmI 2016. Lecture Notes in Computer Science, vol 10069. Springer, pp. 487-496, 2016.

[23] P. Saini, R. Willmann, R. Huurneman, G. Lanfermann, J. te Vrugt, S. Winter, and J. Buurke, "Philips stroke rehabilitation exerciser: A usability test," in Proc. IASTED Int. Conf. Telehealth/Assistive Technol., Anaheim, CA, USA, 2008, pp. 116-122. 